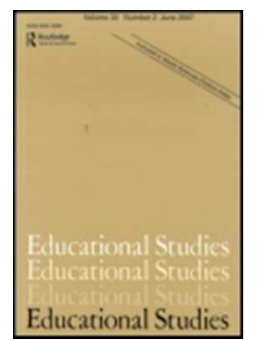

\title{
Children critique learning the 'pure' subject of English in the traditional classroom
}

\begin{tabular}{|r|l|}
\hline Journal: & Educational Studies \\
\hline Manuscript ID & CEDS-2017-0110.R1 \\
\hline Manuscript Type: & Research Paper \\
\hline Keywords: & learning, curriculum, primary school, pupil narratives, Egypt \\
\hline \multicolumn{2}{|l}{} \\
\end{tabular}

SCHOLARONE ${ }^{\text {m }}$

Manuscripts 


\title{
Children critique learning the 'pure' subject of English in the traditional classroom
}

\begin{abstract}
This paper draws on the early work of Basil Bernstein (1971) to make a sociological exploration of the enforcement of strong boundaries between 'pure' (disciplinary) and 'applied' (common-sense) knowledge in primary school English classrooms. This article is innovative in its focus on how pupils describe and evaluate their own experiences. It addressed the research question: How do primary pupils experience the traditional classroom and what suggestions do they and their teachers express for making improvements to English language learning? We used observations in 18 classrooms, a written sentence-starter activity with 394 pupils and extended individual interviews with 38 pupils in Egyptian government primary schools. The research took place in the 2015-6 school year in response to the British Council's ELT research awards funding (ELTRA). This article conveys the pupils' experiences of learning the 'pure' English; and also of experiencing another English outside the classroom, which was legitimised through speaking and interacting rather than through assessed writing. This paper suggests implications for the countries in the Middle East, and further afield, whose public primary schools still emphasise rote learning of the written word more than speaking English for communicative purposes.
\end{abstract}

\section{Introduction: 'pure' versus 'applied' knowledge}

This article takes a sociological view of how disadvantaged primary-aged children value and appropriate school learning, taking the teaching and learning of English as a second language as its focus. Using Bernstein's (1971) theoretical framework, this paper investigates primary classrooms with reference to the enforcement of strong boundaries between 'pure' and 'applied' knowledge. Bernstein described 'strong framing' whereby two varieties of each 
subject domain were opaquely insulated from each other: pure or disciplinary knowledge on the one hand; and everyday, applied, common-sense or community knowledge on the other. Pure knowledge in the case of English, might consist of abstract grammar rules, generalisable principles and lists of vocabulary. A pure English curriculum would assist pupils in 'consciously grasping the systematic interrelationships' among linguistic concepts (White $2012,2)$. In the Egyptian government system, as in other countries of the Middle East and beyond, this English curriculum is taught as a discrete subject at primary school level, in lessons designated as 'English'. In Egypt, pupils also take another subject called 'Arabic' in which they learn a classical form of their mother-tongue, Egyptian Arabic.

The research study that underpinned this article aimed to understand the value of primary school learning to less advantaged Egyptian children (those in the most poorly resourced schools) who were accustomed to strong boundaries between the different disciplines and also between school and community knowledge (strong classification and strong framing). By revealing the comments of the young pupils themselves, we aspire to provoke further reconsideration of the value of primary school English learning in primary classrooms elsewhere in the world, whose public schools also tend to follow the current strongly classified, strongly framed model as used in Egypt (Assassfeh et al 2012; Fairclough 2014; Hoadley 2006; Nunan 2003; Richards and Rodgers 2014). As in Egypt, the public primary schools (state schools) in these areas tend to prioritise 'generative principles' as curriculum content, which are 'separated off from ordinary experience and its pragmatic frames of reference' (Beck 2013, 186). However, very little research has been done among primary pupils in such government primary school systems to investigate how they experience and evaluate them (Holliday, 1994). This article seeks to redress this balance, using disadvantaged Egyptian pupils as the example. These pupils attend the country's most- 
poorly resourced schools and their families have limited disposable income at home and few if any financial savings.

In the strongly-classified system in Egypt, as in other similar countries, the pure subject discipline of English has become associated with a prestigious social identity:
A membership category is established early in an educational career, in terms of an early choice between the pure and the applied... between having and not having a specified educational identity... Subject loyalty is then systematically developed in pupils... therefore, specialization very soon reveals difference from rather than communality with (Bernstein 1971, 55; original emphasis).

The teaching of disciplinary English today, both in Egypt and elsewhere, could be seen, therefore, to be designed to specialize learners' voices with respect to this school code of English and to induct learners into a school 'mode of being', or mode of organizing the English-learning experience, and making meaning of it (Hoadley 2006; Hoadley and Galant 2016). This division in language learning has been referred to as 'institutional' in contrast to 'vernacular' (Barton and Hamilton 2012, xvii). Michael Young, in relation to 'powerful knowledge', suggests: 'Parents send their children to school expecting them to acquire the specialist knowledge that they would not have access to at home' $(2013,107-108)$. Sociologist John Beck describes Bourdieu's position, however, that 'the authoritative verdicts of the legitimated authorities within the cultural field are in reality arbitrary; ... [but] are widely 'misrecognised' as reflecting the relative intrinsic worth of these things' (183). In other words, the traditional value assigned to the discipline of English may in fact be open to critique. Furthermore, as curriculum theorist Albert Kelly (2009) pointed out, the idea itself that some knowledge is more worthwhile than others, can lead to a 'stratification of society, 
to elitism, to the disaffection and alienation of those who find themselves in the lower strata of such a society' (58). Our exploration in this article is particularly important for the least advantaged children because of the tension between their entitlement to access the disciplinary knowledge of English as taught at school on the one hand; and the difficulty of making a connection between this disciplinary knowledge and their (impoverished) lives outside school in which the use of English is different from in school.

Many learning activities in the classrooms we observed in Egypt consisted of students working individually by listening to the teacher and copying lessons from the blackboard. Pupils were expected to accept and digest the pure knowledge, even in primary school. Tests acted as the main vehicles of feedback to individual pupils as Knowledge of Results (KR). This non-critical, individualist and literacy-based culture tended to disregard the vernacular English; and also disregard the extent to which vernacular English was used socially and/or at home among these disadvantaged children. The classroom teacher tended mainly to act as 'primary knower' (Nassaji and Wells 2000) and play a converging function and a certifying function (Lin 2007) that kept pupils strictly to the assessed content of English and indicated when pupils had mastered it accurately. However, the teachers did not use vernacular English nor encourage the speaking of English in class and they tended to ignore pupils' outside-school encounters with this vernacular English.

The outside-school encounters with English for these disadvantaged children would have been much more limited than those of privileged Egyptian pupils. Advantaged pupils would have had more social opportunities for speaking English and hearing the spoken word, through using technology but also through contact with native English speakers and the habit of more wealthy Egyptians, of using English as a second language in social situations. 
However, for the less advantaged pupils in our study, access to English outside school was likely to have been very limited and thus their initiation into English culture would have been minimal. What was noticeable was that, in their formal classrooms, little attempt was made to compensate for pupils' lack of exposure to spoken, everyday English outside the classroom. The emphasis was on transmitting the written curriculum, regardless of pupils' exposure to the spoken language.

A contrasting model of the state primary school was described by the British Plowden Report of 1967 as being:
A community in which children learn to live first and foremost as children and not as future adults... [The school] insists that knowledge does not fall into neatly separate compartments and that work and play are not opposite but complementary. A child brought up in such an atmosphere at all stages of his [her] education has some hope of becoming a balanced and mature adult and of being able to ... look critically at the society of which [s] he forms a part (cited by Dann 2002, 21).

In other words, at that time (1967, just before Bernstein was writing), an explicit aim of primary schooling in England was to initiate pupils into knowledge which would gradually help them to be people who could manage and contribute to the society that they lived in. Primary schools could be seen as the introductory stage for disciplinary knowledge. During this stage, pupils brought their everyday experiences into school and these mingled with more structured academic inputs. Seven years of primary school initiation prepared them for approaching the more highly classified and tightly framed curriculum of secondary school.

Primary pupils in Egypt today have very little if any chance for such initiation, starting formal disciplinary English lessons in Year 1. Michael Young (2013) has suggested that access to this 5 
pure disciplinary knowledge conveys power on its acquirers precisely because it allows them to participate in discourses within society which in turn give learners the opportunity to look critically at society and contribute meaningfully to it. With access to such powerful knowledge, he argues, learners will no longer be dependent on others who own such knowledge. This pure knowledge, he suggests, brings learners beyond their common-sense understandings of their daily experiences and enables them to conceive of alternative and new possibilities beyond these daily experiences. However, having access to this disciplinary knowledge and being able to use it in these ways is very complex, especially when the disciplinary knowledge is imposed on learners at such a young age, and when they have had little time to develop informed 'common-sense' concepts. John Beck (2013) suggests that even at higher levels of schooling:

Enabling students to make subjectively meaningful connections between these necessarily remote disciplinary worlds and the student's everyday experience may prove to be one the most challenging and enduring educational problems that face us (187; original emphasis).

Our study interrogated some Egyptian primary pupils' comments about these connections between the disciplinary and the common-sense knowledge of English. Through our study, we aimed to consider in detail how these connections between classroom learning and community learning may be facilitated, and what the implications are for underprivileged pupils' wellbeing. We look for messages relevant both to the primary schools of Egypt and to those of other countries sharing similarly closely classified and tightly framed curriucla, in relation to the common aim of improving the social justice of all societies. 


\section{Research design}

The research question for this study was: How do primary pupils experience the traditional classroom and what suggestions do they and their teachers express for making improvements to English language learning? The aim was to elicit and understand in depth how disadvantaged primary school pupils perceived their experiences of learning English, in a school system whereby boundaries between school and community knowledge were strong, and the pupils' control of the classroom was weak. The research questions were deliberately open-ended in order that as researchers we did not impose assumptions on pupils. Our starting point was the recognition that little interaction occurred between pupil and teacher or pupil and pupil in these language classrooms and we wanted to investigate the sense pupils made of learning language without planned occasions for practising it orally. We knew that in better-resourced schools, such as privately owned 'international' schools in Egypt, this traditional approach had been somewhat dismantled.

Our methodology was interpretivist whereby we valued and explored the interpretations and meanings expressed in individual pupils' narratives. We agreed with Saunders et al. $(2007,106)$ that this paradigm adopted an 'epistemology that advocates the need for the researcher to understand the differences between humans in their role as social actors'.

As a team of researchers, two Egyptian and one English, we used four data collection methods in two stages of research:

First stage: November 2015

1. Observation of 18 lessons, including English lessons, in three schools attended by disadvantaged pupils in Alexandria, Egypt;

2. Written responses of 393 pupils in these lessons to sentence-starters. 
Second stage: April 2016

3. Individual interviews with 38 pupils; and

4. Group Interviews with English teachers in each school.

The research context was the English language teaching of poorly-resourced primary schools in Egypt. Access to state schools in Egypt is exceptionally difficult to obtain but we managed to gain access in Alexandria, Egypt, to three primary schools of different types: one Islamic school; one 'official language' school; and one 'mainstream' school. In the first two schools, as is common even in the least privileged communities in Egypt, some minimal fees were paid by parents; and in the third, no fees were paid at all. These latter are the least privileged schools in the country. Altogether we had the following participants:

Islamic school $=88$ pupils [27 BOYS; 61 GIRLS].

Official language school = 196 pupils [92 BOYS; 104 GIRLS].

Mainstream school $=110$ pupils [61 BOYS; 49 GIRLS].

TOTAL = 394 PUPILS

Girls $=\mathbf{2 1 4}$

Boys $=180$

However, one girl declined to complete the sentences so the total number of sentencestarter tasks completed was 393.

Observation

In each school, we observed lessons of three classes of Year 5 pupils [aged 9-11 years]. To familiarise the pupils with ourselves, we firstly observed each research class during a lesson 
in a subject other than English. The three of us next observed and made field-notes about an English lesson for all the classes. Each of us researchers focused on a particular group of pupils in class and we were non-participant during the lesson. After each observation, the three of us compared our observations and collated our notes. Our main focus was the relationship between the actions of the teacher and the responses of the pupils. In particular, we noted: pupils' opportunities for collaboration, talking in English, using selfassessment, receiving formative teacher feedback, engaging in differentiated tasks, engaging in dialogue with the teacher, having choice and linking learning to home.

\section{Sentence-starters}

After the observed English lesson, the three of us (researchers) worked together to present the sentence-starters to pupils. The sentence-starters were based on the lead author's previous research in primary classrooms, where this data collection method was designed and trialled (see Author $2015 ; 2016 ; 2017)$. The aim of the prompts was to point respondents in the relevant direction without leading them to particular ideas. They were an innovation in researching with pupils, based on the metalearning literature of Chris Watkins (2015) in which even very young pupils explore aspects of their own experiences in classrooms.

We took time to explain to pupils in detail what the purpose of the research was and what we would do with findings. We also answered their questions about the research. We explained that pupils' individual names would never be revealed in publications of findings (pseudonyms are therefore used for pupils and teachers, below, without reference to their schools). We gained the pupils' face-to-face consent before carrying out any activities with 
them. We also gained the teachers' and principal teachers' written consent. This research, both in its design and fieldwork, therefore adhered to the BSA ethical guidelines (2002). In every classroom, as children completed the sentences, the two Egyptian researchers in our team went around the class giving support where necessary, but without putting any answers into pupils' minds. The responses were transcribed and translated by our two Arabic-speaking team members. The sentence-starters included the following:

1. In the English class where I benefit most, I feel...

2. The things I do in the English class where I benefit most are...

3. The things I do in the English class which do not benefit me are...

4. The teacher who helps me learn best is...

5. I want to learn English so that I ...

\section{Individual interviews}

Individual interviews were our key source for investigating pupils' complex insights. Although we invited nearly 400 pupils to write responses to sentence-starters, by interacting individually with 38 carefully selected interviewees, we were able to ask and respond to diverse questions and thereby explore identified issues in depth. We selected the 38 interviewees by reading through the sentence-completions and selecting those who appeared to be most engaged with the topic of research. We were careful to select both those who could write well and those who could not, as well as those who were outspoken and those who were withdrawn. Interviews lasted between nine and 51 minutes. Most of them were therefore in-depth and we were able to probe many topics raised by the pupils themselves, relevant to our study. The structure of each interview was fluid and led by the 
interviewee, depending on their responses to the sentence-starters. We did also ask every pupil about: their favourite subject; their parents' occupations; their own aspirations; their experiences of learning English in the classroom; and their recommendations for change.

We asked each school to provide us with a quiet, private room in which to carry out the interviews where possible. All interviews were audio-recorded and transcribed. Each child gave her/his specific permission to be interviewed and also to be audio-recorded in every case. One pupil declined to be interviewed. Seven girls were interviewed in each school. Six boys were also interviewed in two schools, five boys in the third.

Teacher Group Interviews

We led Group Interviews with primary English teachers in each school:

\section{Group Interviews}

Islamic school: 1 hour 53 minutes; 9 teachers

Official language school: 1 hour 30 minutes; 6 teachers

Mainstream school: 1 hour; 4 teachers.

The aim of the Group Interview was to hear the perspectives of the teachers about pupils' responses to the sentence-starters. In each Group Interview, we presented one pupil sentence-completion at a time and we invited the teachers to predict how the pupils would have responded during the sentence-completion exercise. We then fed back to them the actual responses from the pupils across the three schools. Finally, we invited the teachers to reflect on and comment on all the pupil responses and make suggestions. 
12

\section{Analysis}

As a team, we analysed responses using inductive approaches whereby we tried not to impose our own categories on the pupils' (or teachers') responses but rather attempted to let themes emerge. We based our approach on the grounded theory described by Charmaz (2014). In our presentation of themes that emerged, we have aimed both to indicate dominant trends and to illustrate insightful special cases. 


\section{FINDINGS}

\section{Pupils aspired to improve their social identities through grasping English as a 'pure' school subject}

The primary school English lessons we observed during our research project took place in classrooms where desks were positioned to focus on the teacher's concentrated transmission of disciplinary content. Each teacher presented the lesson by writing English grammar rules and vocabulary on the board for children to copy down into their exercise books. S/he then read out what s/he had written and asked children to chorus in repetition. Occasionally s/he asked a question to everyone and would select one pupil to answer the question aloud. The pupils therefore mainly sat silently, listened and copied work down into their books. Our subsequent work with teachers suggested to us that this approach was rarely questioned, even by the most energetic of teachers. Indeed, it seemed difficult for teachers to even imagine anything different.

We were somewhat surprised initially to find that pupils seemed to be engaged and concentrating well on the lesson. In Bernstein's own words, they seemed to possess 'a passive willingness to accept "doses of training and retraining as prescribed by government"' (Beck 2013, 181 citing Bernstein, 2000). This behaviour was explained somewhat when we interviewed pupils. We found that these children had very high ambitions for their futures and believed that learning pure, school English was instrumental in helping them to achieve these ambitions. Underlying pupils' aspirations, there seemed to be a concept of an 'educated' citizen (Peters 1965) who knew the pure English and because of this, had prestige in society, as suggested by Bernstein (1971). They aspired to become this educated citizen in order to have status in society. In the 393 sentence-completion responses, there were 87 
pupils who specifically mentioned becoming educated by learning English and 74 pupils who described wanting to learn English to improve the 'level' of their lives. There were 89 pupils who mentioned getting a good job or working in a university through their command of English; while no fewer than 58 pupils detailed wanting to learn English to become a doctor specifically.

It is noticeable that they aspired to become a more 'educated' person than their parents had been, with a more socially prestigious job and a higher 'level' of life. For example, ten out of the 38 interviewees aspired to become doctors and six to become engineers and for both, high level English was required for study at university. In contrast, there were no interviewees' parents described as doctors and only two as engineers. Parents' semi-routine or routine work included factory worker, taxi driver and hotel worker. Ten interviewees told us that their mothers were housewives but not a single girl suggested that she would become a housewife. What we noticed, in other words, was that these pupils were seeking to become educated and improve their future careers over those of their parents, to work in more elite professional jobs than their parents. Learning English as a school subject featured in their responses as one crucial way to make this social move. In other words, we perceived that the pupils saw English both as intrinsically worthwhile in Peters' (1965) sense as constituting the educated person; but also as a powerful tool for social mobilisation in Young's (2013) sense. What is also clear is that these pupils sought to fit in with the social definition of an educated person in their culture and then to use their subject knowledge to improve their own position within that society - rather than changing the society itself in a critical way.

Pupils were adamant about the importance to them of acquiring the disciplined knowledge 14 
provided by the teacher, even if the pupils told us that they often found grammar rules and structures very hard to grasp. For most students, therefore, the main emphasis was on having a teacher who could 'explain the lesson' clearly, which was the key ingredient in their acquisition of the designated knowledge. This referred especially to grammar rules and structures. Hana reflected this common view. She told us about the ideal teacher:

She explains quietly, step-by-step. She does not shout. She explains in a quiet and gradual manner. She does not get irritable easily. She repeats her explanation when someone has a problem understanding. When a student tells her that she does not understand something, she does not insult them or call them names... She explains again instead.

Hana reflected many other pupils' views in her emphasis on the teacher's kindness but without challenging the teacher's role as that of knowledge transmitter of a particular and essential body of knowledge that was not easy to access directly. Furthermore, most pupils believed that some harsher discipline processes were justified to some extent as the only way to transmit difficult curriculum content effectively. Mahmoud told us that for 'weak' students who failed to understand well, 'We give them a chance and if they keep making mistakes we hit them'. In other words, this punitive culture was accepted by many pupils as the best, perhaps only, way to get pupils to reach the challenging, prerequisite level of the English curriculum in the right amount of time.

Many pupils' persisting focus on learning via the written word rather than on conversational English, was highlighted when we asked children about how they would teach a foreign child Arabic. They seemed to find it hard to conceive of language learning through speaking and listening. They recommended teaching the foreign child to learn the 
alphabet in Arabic first and to read vocabulary before allowing the foreign child actually to use the language. For example, Rana believed the following when we asked her advice for a foreign child learning Arabic:

If he [a foreign boy] learns the alphabet, he can form any word... When he learns the alphabet, he can learn words and sentences. I will make him practise saying the words he needs. If he knows the words, he can form the sentences on his own.

Surprisingly, even the internet was seen by some pupils as a source of information to help pupils memorise rules and vocabulary rather than a site for learning to speak as well as read and write. For example, Mahmoud explained how, if teachers had access to IPads or tablets, they should: 'Ask the pupils to use their tablets to search dictionaries and then ask them to recite what they learnt'. In other words, he was not asking for new content of English lessons, only a new instrument to deliver traditional content to help them to better meet the traditional goals of becoming educated.

\section{Pupils engaged in outside-school English language learning to supplement the school} curriculum

Given these findings, we were surprised to discover that, when asked through the sentence-completions about their key motivation for learning English at school, the largest proportion of both boys and girls chose speaking English ( $n=166)$; and learning English to travel abroad ( $n=138$ ). The chances of these disadvantaged pupils actually travelling abroad at any time in their lives were in reality minimal. However, these aspirations illustrate that they were not only interested in being educated in the school's pure English, despite its current and future potential advantages, but they also wanted to be able to apply it by speaking it. At present, applying or speaking English rarely occurred in the 
school classrooms and the use of peers as practice-partners was almost non-existent. No examples of spontaneous or open-ended English speaking were observed in the classes we attended. Only occasional structured interaction with the teacher was detected. Despite this, it seemed that the pupils had perceived a need to use their English as well as to learn the pure form. It appeared then, that pupils still aimed to improve their social status, but did not see the learning of classroom English as the only means for achieving this. There appeared to be some tension between the two Englishes they aspired to learn. On the one hand was the pure English that was a sign of being educated and that allowed them to pursue prestigious subjects at university and thus progress socially via the traditional route. On the other hand, however, these disadvantaged students did seem to be questioning the completeness of the pure English in terms of serving their current and future needs.

Our analysis led us to believe that pupils' desire to speak English related to the pupils' 'imagined community' of English speakers whom they perceived as a community of educated, high status, international people who inhabited 'advanced' countries and who spoke English (Anderson 1991; Kanno and Norton 2003; Norton, 2001; Norton and Kamal 2003). Therefore, contrary to expectation, these children were not only trying to pass their school exams to achieve elite status as doctors and engineers but they perceived - albeit faintly as yet - another route to join an elite as well. This alternative route was that of joining the international English-speaking community, whose English was different from classroom English, yet a related and potentially legitimate means for social mobility. Reem explained: 


\author{
When I travel abroad, I need English to finish deals with business people. They don't \\ speak Arabic and I want to speak English not Arabic so that I could do whatever \\ business I want.
}

Merna reflected her desire to identify fully with the imagined community, not only as a business person:

I would like to ... travel abroad and to be able to talk to people there and be like one of them. I wish to live abroad... I wish I could be like them and speak English like them.

These pupils emphasized the importance of learning beyond the teacher in the classroom. They referred to some online methods, similar to the online methods used outside school by English pupils (Furlong and Davies 2012). However, in Egypt, online learning was only one possible means (sometimes also not possible) among a range of pupils' suggestions for speaking and listening to English outside school. In these examples, they were showing some challenge to the control of the teacher over their limited subject domain. For example, Ossama advised other pupils:

They should search the internet and read subjects and not rely only on the school ... you shouldn't depend on the teacher. You should have access to other resources...

Reem, among others, had noticed that pupils who took initiatives in improving their English in diverse ways beyond the reach of the teacher, seemed to be more immersed in the English language generally:

Those who are very good at English watch lots of films and depend on themselves... the more we listen [to other English speakers], the more we learn. 
One teacher noted this tension between the (disciplinary) content taught by teachers and the (spoken) English taught by others. This teacher mentioned 'real life':

In real life, when they [pupils] listen to English songs, someone speaking English, they feel that they haven't learnt English at all [at school].

The teachers thereby also seemed to be questioning the completeness of the pure English of the classroom teacher and recognising the value of applied English, especially for these students who were from underprivileged backgrounds.

Some pupils in our study had discovered more participatory means for learning English including interactive activities in which another English speaker might provide them with feedback by modelling English. They noticed that this English could contain any number of words and sentence structures that they had not officially 'covered' in lessons. During this process of adding to the school English lessons, a few pupils had begun to encounter other models of English itself: this was perhaps how they realised that classroom English was not the only English that they needed to learn in their pursuit of social success. They had discovered that they could, and perhaps should, use siblings, parents, tourists and YouTube to engage in learning conversations, in addition to learning the school English. For example, although Merna was clear that in class the pupil's role was to be silent and to pay attention to the teacher, at home she would follow up any questions she had by making up her own sentences to use with her parents. Merna explained:

I study the English words by heart but if there is a word I cannot read my father will read it for me... when I learn a new word in English, I try to put it in a sentence and say it to my mother. 
Perhaps the most striking example of a pupil engaging in diverse means for learning the spoken language was Yulia's vivid picture of learning English by playing games using the English language with her older sister:

We just play a game [using English] of characters, animals and birds... We also talk about films [in English]. I usually check if she understands me or not and she does the same with me... We get videos from YouTube and talk about them.

However, it is important to note that such support was only available to those pupils whose parents or siblings spoke some English or who could afford to pay an expert private tutor. Ossama explained how, when accessing additional resources, he would use digital sites to listen to spoken English. However, this access also depended on the availability of particular (expensive) English language TV channels:

When I watch Disney Channel and listen to them speaking English all the time, I listen to them and learn new expressions. I mean, it helps me to learn good English.

When we asked Meera in interview how Egyptian pupils could learn to speak like the characters she encountered in English-medium films, she paused, then replied: 'But we can't be like them'. After further pause, she changed her mind and decided that such learning could occur - but not in school classrooms:

Meera: But we could speak like them if we had courses.

MM: Where could you have courses? In schools?

Meera: No!

MM: So where would these courses be taught?

Meera: In institutes ... any place. 
For her, the school's role was to teach one English while outside school, students could learn a different kind of English, applied English, in a range of different ways. Pupils with enough resources could attend 'institutes' and/or take private lessons to learn the remaining aspects of English.

Our analysis of this situation relates to the need for pupils' prolonged informal initiation (Beck 2013, 189) in order to access entry into the aspired community. It seems that these pupils were aware of an alternative English that was part of the 'cultural capital' necessary to make social progress. Some of them had some inkling, as yet indistinct, that disciplinary English, transmitted by the teacher, was essential but not sufficient. Some pupils mentioned that Egyptian children who attended English-medium (international) schools thereby had easy access to that additional set of qualities that were needed to become part of the elite. At age 10, the sample pupils still had high, albeit perhaps unrealistic, hopes to overcome the obstacles of disadvantage, using an array of rather random out of school methods. But at age 16 , as they enter the stiff competition for university places, it is intriguing to know how they will perceive their chances then. Another research project needs to address this topic.

\section{Peer learning and its potential for connecting the pure English to the applied English}

It was noticeable from our observations that almost no sanctioned peer learning seemed to be occurring inside the English classroom. It actually became clear during individual interviews that pupils found it hard to imagine that other pupils could be part of their learning in the classroom. Several pupils said they preferred to work alone and have the teacher correct their mistakes. For example, Moussa said: 'We prefer teachers' corrections more as we are used to it and the teacher knows better... it is the teacher's work'. In other 
words, he hinted that the purpose of learning was to acquire the true English owned by the teacher and to have impurities stamped out immediately by the teacher.

On the other hand, there were some interviewees who saw a role for peer correction to support the learning of classroom English. For example, one pupil, Donia, saw that: 'When I make a mistake and [peers] correct me, I know that I have made a mistake and I will learn from mistakes'. Going beyond mistake-correction, however, a small handful of children proposed some further diffusion of teaching, in the form of pairwork among pupils in the classroom which entailed pupils actually constructing spoken sentences in which they applied the pure knowledge to the spoken word. Mostafa, for example, proposed that if he were the teacher:

I would pair them [pupils] to ask and answer each other... There are passages they would read and they would form sentences using the words in the passage.

In the individualist culture that had been nurtured to protect the purity of the subject, this lack of experience with collaboration was not surprising. However, its lack appears to mitigate against these pupils' acquisition of the very knowledge that their poverty obstructed, the means for connecting their curriculum knowledge to everyday life beyond the school. Families with more resources did not need their children to practise speaking English in the classroom as they had opportunities for practising English outside school. In addition, they were more likely to have access to the internet than less advantaged pupils. These privileged children needed the disciplined knowledge of the classroom as the aspect of curriculum that they could not access informally. For the disadvantaged pupils, however, the classroom might be the best opportunity they had for connecting the institutional and the vernacular and becoming more initiated into the culture of English in its wider social sense. 


\section{The potential of pupils learning the spoken word through the internet}

One means whereby the pupils in our sample could improve their immersion into the wider culture of the English language was through the internet. However, because of their lack of resources, the internet was neither widely accessed nor widely used for learning by the pupils in our sample. However, among a few interviewees, there were some quite innovative ideas about teachers harnessing digital technology to teach an expanded version of English in the classroom which sometimes included a focus on the spoken language. This of course would depend on internet being available in schools and in pupils' homes, which was not always the case. Reem had some insightful ideas, in cases where internet was available:

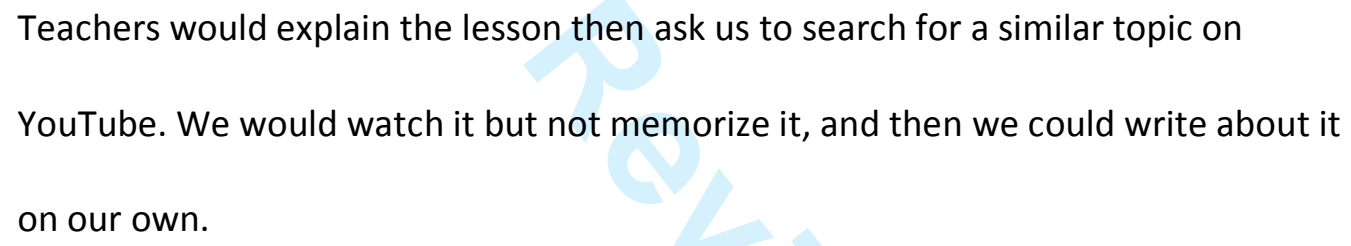

Merna noted the collaborative potential of preparing (written) work at home to then share in class:

[We could] use the internet to write our own topics and prepare PowerPoint presentations with pictures and writing. I would access useful sites and chat with my friends and we could use the camera to see each other.

Lobna, among others, proposed teachers using a laptop with pupils to show 'how pupils in England talk' and also 'how pupils [in England] learn'. It seemed that she almost perceived the traditional teacher as a barrier to her full English learning:

I want technology... I need a small Ipad instead of textbooks because now pupils like Ipads not textbooks... If they had Ipads, they would interact with each other. 


\section{Educational Studies}

Carmen suggested a different solution to the disconnection between disciplinary and common-sense knowledge:

We can have the school book on the internet. It will be easy to study and I will like English. It will be better than taking private lessons. I will speak in English... I and my friends can learn together and share things over the internet.

These pupils wanted to add to the insulated content and tightly framed pedagogy of the classroom, to embody a less strongly-framed pedagogy whereby outside stimuli could be incorporated, especially drawing on the spoken (applied) word as used among communities of English speakers. In these select examples, the pupils indicated that they were already engaging in, or prepared to engage in, additional - applied - English knowledge but that they wished for this to be introduced into the classroom so that all pupils could benefit from it, not only the more privileged.

\section{Discussion: mitigating against disadvantage by challenging the pure curriculum}

Our research question was: How do primary pupils experience the traditional classroom and what suggestions do they and their teachers express for making improvements to English language learning? By analysing the words of the 394 underprivileged pupils in our study, in particular those of 38 interviewees, we perceived that they described experiencing English learning in two distinct senses: acquisition of English in the traditional classroom as the pure school discipline, which they believed was the passport for them to become more prestigious within traditional structures of society; and immersing themselves in verbal interaction with others, which they believed would enable them to become part of a wider community and enhance their identities in an alternative (albeit related) way. This dichotomy was of interest in terms of considering the nature of knowledge that is valuable 
to disadvantaged pupils. Although pupils in this research conformed to traditional approaches in many ways, there were signs that they needed something more, if they were to achieve their desire of becoming part of an international English speaking community who had high status globally and in their country too.

In relation to the second part of our research question, suggestions of pupils for making improvements to English language learning, what became evident from our pupils' narratives, was that some children seemed to believe that to qualify as valuable English knowledge, the English subject in the classroom should include spoken (applied) aspects, useful in everyday life. In other words, they were questioning the adequacy of the pure English in the traditional classroom, disconnected from the applied English, in terms of its potential usefulness. Within their expanded models of learning English, pupils described situations where learning tasks and activities were more interactive than currently in the classroom. Relations in such a learning environment would become more diffuse and less concentrated between learner(s) and teacher(s). If this expanded framework of applying English language knowledge were incorporated within the classroom, pupils who had little or no access to conversational English outside school could at least obtain some exposure to it in the classroom. In addition, they might also find the experience of learning English more active and perhaps enjoyable.

It may be that these disadvantaged pupils themselves had come to experience and perceive how traditional 'specialization' on its own kept them apart from, rather than in 'communality with' a wider (this time more privileged) community (Bernstein 1971, 55; original emphasis). In terms of social justice, the implications of this finding were that opportunities for speaking in the classroom needed to be increased, whether through more use of digital technology in 


\section{Educational Studies}

class (if internet were available) or through use of peers in the classroom for practising speaking. It seems that for these less advantaged children, digital technology was not often available outside school. The school would therefore do them a service by making it more available inside school if possible. This would mean that, while these children could not benefit outside school from the English language on the internet as did their more advantaged peers, at least they could brush with these opportunities within class.

More simply, however, pupils perceived and expressed that their lack of experience with the niceties of the spoken language outside school, at home and socially, could be compensated for by more interactive learning tasks within the classroom. If their families and friends did not have familiarity with spoken English, at least the children themselves could gain some practice by speaking with peers in the classroom. One simple way of managing even in large classrooms, as suggested by the sample interview pupils, is using pair work whereby every pair of children in the classroom practises certain sentences with each other, all at the same time. This way, every single child has a chance to practise the spoken word, every lesson. This is a message that traditional classrooms in other countries, for example, in the Middle East and beyond, might find useful too, if they currently sustain insulation among subjects and strong boundaries between pure and applied knowledge.

Change of the nature of classroom behaviours is likely to be resisted by the traditionally more privileged strata of societies because of its challenges to elitist structures of power, authority and identity. This is because the elite have their own (private) access to ways of completing their process of becoming 'educated' through initiation at home and in social life. However, a progressive shift which benefits the less advantaged in society will be helped by a new pedagogy based on the explicit linking of the traditional curriculum to the language of 
communication used globally and locally. In Egypt, a pedagogy including frequent opportunities for pair work among all members of the class simultaneously will be well suited to the large numbers in Egyptian classrooms. At the same time, it will help to provide opportunities for less advantaged pupils to link principled knowledge to applied English in a more 'subjectively meaningful way', as expressed by pupils in our sample. In Young's words, cited earlier: 'Parents send their children to school expecting them to acquire the specialist knowledge that they would not have access to at home' $(2013,107-108)$. In the case of less advantaged children in Egypt, as in similar countries, ironically this specialist knowledge may transpire to include vernacular English.

\section{REFERENCES}

Anderson, B. 1991. Imagined Communities: Reflection on the Origins of Nationalism. Verso: London.

Asassfeh, S., Khwaileh, F., Al-Shaboul, Y., \& S. Alshboul. 2012. Communicative Language Teaching in an EFL Context: Learners' Attitudes and Perceived Implementation. Journal of Language Teaching and Research, 3(3), 525-535.

Author 2015

Author 2017

Barton, D., and Mary Hamilton. 2012. Local Literacies: Reading and Writing in One Community. London: Routledge.

Beck, J. 2013. Powerful Knowledge, Esoteric Knowledge, Curriculum Knowledge. Cambridge Journal of Education 43(2): 177-193. 
Bernstein, B. 1971. On the Classification and Framing of Educational Knowledge, in: M. Young (Ed) Knowledge and Control (pp.47-69). London: Collier MacMillan.

Bernstein, B. 2000. Pedagogy, Symbolic Control and Identity: Theory, Research, Critique. Lanham, MD: Rowman \& Littlefield.

BSA, British Sociological Association. 2002. Statement of Ethical Practice. http://www.britsoc.co.uk/media/27107/StatementofEthicalPractice.pdf

Charmaz, Kathy. 2014. Constructing Grounded Theory. London: Sage.

Dann, R. 2002. Assessment as Learning. London: RoutledgeFalmer.

Fairclough, N. 2014. Critical Language Awareness. London: Routledge.

Freire, P. 1970. Pedagogy of the Oppressed. London: Penguin.

Furlong, J. and Chris Davies. 2012. Young People, New Technologies and Learning at Home:

Taking Context Seriously." Oxford Review of Education 38, no. 1 (2012): 45-62.

Hoadley, U. 2006. Analysing Pedagogy: The Problem of Framing. Journal of Education 40: 15-

34.

Hoadley, U. \& J. Galant. 2016. Specialization and School Organization: Investigating

Pedagogic Culture. British Journal of Sociology of Education 37(8): 1187-1210, DOI:

$10.1080 / 01425692.2015 .1042149$

Holliday, A. 1994. Appropriate Methodology and Social Context. Cambridge: Cambridge University Press.

Kanno, Y., \& B. Norton. 2003. Imagined Communities and Educational Possibilities:

Introduction. Journal of Language, Identity, and Education 2(4): 241-249. 
Lin, A.M. 2007. What's the Use of 'Triadic Dialogue?': Activity Theory, Conversation Analysis, and Analysis of Pedagogical Practices. Pedagogies: An International Journal, 2, 2, 77-94.

Liao, X. 2004. The Need for Communicative Language Teaching in China. ELT journal, 58(3), 270-273.

Nassaji, H., \& G. Wells. 2000. What's the Use of 'Triadic Dialogue'?: An Investigation of Teacher Student Interaction. Applied Linguistics 21: 376-406.

Norton, B. 2001. Non-participation, Imagined Communities and the Language Classroom. Learner Contributions to Language Learning: New Directions in Research 6(2): 159-171.

Norton, B. \& F. Kamal. 2003. The Imagined Communities of English Language Learners in a Pakistani School. Journal of Language, Identity \& Education 2 (4): 301-317.

Nunan, D. 2003. The Impact of English as a Global Language on Educational Policies and Practices in the Asia-Pacific Region. TESOL quarterly, 37(4), 589-613.

Peters, R.S. 1965. Education as Initiation, in R.D. Archambault (Ed.): Philosophical Analysis and Education (pp. 87-111). London: Routledge \& Kegan Paul.

Richards, J. C., \& T. S. Rodgers. 2014. Approaches and Methods in Language Teaching. Cambridge University Press.

Saunders, M., P. Lewis, \& A. Thornhill. 2007. Research Methods for Business Students. Prentice Hall: London.

Watkins, C. (2015). Meta-learning in Classrooms. In [Author].

White, J. 2012. Powerful knowledge: Too Weak a Prop for the Traditional Curriculum. New Visions for Education Group, available at http://www. newvisionsforeducation. org. uk/2012/05/14/powerful-knowledge-too-weak-a-prop-for-the-traditionalcurriculum. 
30

Young, M. 2013. Overcoming the Crisis in Curriculum Theory: A Knowledge-based Approach. Journal of Curriculum Studies 45(2): 101-118. 
Formatted: Font: $12 \mathrm{pt}$

This paper draws on the early work of Basil Bernstein (1971) to make a sociological exploration of the enforcement of strong boundaries between 'pure' (disciplinary) and 'applied' (common-sense) knowledge in primary school English classrooms. This article is innovative in its focus on how pupils describe and evaluate their own experiences. It

Formatted: Font color: Red addressed the research question: How do primary pupils experience the traditional classroom and what suggestions do they and their teachers express for making improvements to English language learning? We used observations in 18 classrooms, a written sentence-starter activity with 394 pupils and extended individual interviews with 38 pupils in Egyptian government primary schools. The research took place in the 2015-6 school year in response to the British Council's ELT research awards funding (ELTRA). This article conveys the pupils' experiences of learning the 'pure' English; and also of experiencing another English outside the classroom, which was legitimised through speaking and interacting rather than through assessed writing. This paper suggests implications for the countries in the Middle East, and further afield, whose public primary schools still emphasise rote learning of the written word more than speaking English for communicative purposes.

\section{Introduction: 'pure' versus 'applied' knowledge}

This article takes a sociological view of how disadvantaged primary-aged children value and appropriate school learning, taking the teaching and learning of English as a second language as its focus. Using Bernstein's (1971) theoretical framework, this paper investigates primary classrooms with reference to the enforcement of strong boundaries between 'pure' and

\section{1}




\section{Educational Studies}

mother-tongue, Egyptian Arabic.

The research study that underpinned this article aimed to understand the value of primary school learning to less advantaged Egyptian children (those in the most poorly resourced schools) who were accustomed to strong boundaries between the different disciplines and also between school and community knowledge (strong classification and strong framing). By revealing the comments of the young pupils themselves, we aspire to provoke further reconsideration of the value of primary school English learning in primary classrooms elsewhere in the world, whose public schools also tend to follow the current strongly classified, strongly framed model as used in Egypt (Assassfeh et al 2012; Fairclough 2014; Hoadley 2006; Nunan 2003; Richards and Rodgers 2014). As in Egypt, the public primary schools (state schools) in these areas tend to prioritise 'generative principles' as curriculum content, which are 'separated off from ordinary experience and its pragmatic frames of reference' (Beck 2013, 186). However, very little research has been done among primary pupils in such government primary school systems to investigate how they experience and 
The teaching of disciplinary English today, both in Egypt and elsewhere, could be seen, therefore, to be designed to specialize learners' voices with respect to this school code of English and to induct learners into a school 'mode of being', or mode of organizing the English-learning experience, and making meaning of it (Hoadley 2006; Hoadley and Galant 2016). Barton and Hamilton $(2012$, xvii) have referred to-Tthis division in language learning $\underline{\text { has been referred to specifically as 'institutional' in contrast to 'vernacular' (Barton and }}$ Hamilton 2012, xvii). As-Michael Young, in relation to 'powerful knowledge', suggests: 'Parents send their children to school expecting them to acquire the specialist knowledge that they would not have access to at home' $(2013,107-108)$. Sociologist John Beck describes Bourdieu's position, however, that 'the authoritative verdicts of the legitimated authorities within the cultural field are in reality arbitrary; ... [but] are widely 'misrecognised' as reflecting the relative intrinsic worth of these things' (183). In other words, the traditional 3 


\section{Educational Studies}

value assigned to the discipline of English may in fact be open to critique. Furthermore, as curriculum theorist Albert. $\forall$. Kelly (2009) pointed out, the idea itself that some knowledge is more worthwhile than others, can lead to a 'stratification of society, to elitism, to the disaffection and alienation of those who find themselves in the lower strata of such a society' (58). Our exploration in this article is particularly important for the least advantaged children because of the tension between their entitlement to access the disciplinary knowledge of English as taught at school on the one hand; and the difficulty of making a connection between this disciplinary knowledge and their (impoverished) lives outside school in which the use of English is different from in school.

Many learning activities in the classrooms we observed in Egypt consisted of students working individually by listening to the teacher and copying lessons from the blackboard. Pupils were expected to accept and digest the pure knowledge, even in primary school. Tests acted as the main vehicles of feedback to individual pupils as Knowledge of Results (KR). This non-critical, individualist and literacy-based culture tended to disregard the vernacular English; and also disregard the extent to which vernacular English was used socially and/or at home among these disadvantaged children. The classroom teacher tended mainly to act as 'primary knower' (Nassaji and Wells 2000) and play a converging function and a certifying function (Lin 2007) that kept pupils strictly to the assessed content of English and indicated when pupils had mastered it accurately. However, the teachers $y$ did not use vernacular English nor encourage the speaking of English in class and they tended to ignore pupils' outside-school encounters with this vernacular English.

The outside-school encounters with English for these disadvantaged children would have been much more limited than those of privileged Egyptian pupils. Advantaged pupils would 4 
have had more social opportunities for speaking English and hearing the spoken word, through using technology but also through contact with native English speakers and the habit of more wealthy Egyptians, of using English as a second language in social situations. However, for the less advantaged pupils in our study, access to English outside school was likely to have been very limited and thus their initiation into English culture would have been stuntedminimal. What was noticeable was that, in their formal classrooms, little attempt was made to compensate for pupils' lack of exposure to spoken, everyday English outside the classroom. The emphasis was on transmitting the written curriculum, regardless of pupils' exposure to the spoken language.

A contrasting model of the state primary school was described by the British Plowden Report of 1967 as being:

A community in which children learn to live first and foremost as children and not as future adults... [The school] insists that knowledge does not fall into neatly separate compartments and that work and play are not opposite but complementary. A child brought up in such an atmosphere at all stages of his [her] education has some hope of becoming a balanced and mature adult and of being able to ... look critically at the society of which [s] he forms a part (cited by Dann 2002, 21).

In other words, at that time $(1967$, just before Bernstein was writing), an explicit aim of primary schooling in England was to initiate pupils into knowledge which would gradually help them to be people who could manage and contribute to the society that they lived in. Primary schools could be seen as the introductory stage for disciplinary knowledge. During this stage, pupils brought their everyday experiences into school and these mingled with 


\section{Educational Studies}

more structured academic inputs. Seven years of primary school initiation prepared them for approaching the more highly classified and tightly framed curriculum of secondary school.

Primary pupils in Egypt today have very little if any chance for such initiation, starting formal disciplinary English lessons in Year 1. Michael Young (2013) has suggested that access to this pure disciplinary knowledge conveys power on its acquirers precisely because it allows them to participate in discourses within society which in turn give learners the opportunity to look critically at society and contribute meaningfully to it. With access to such powerful knowledge, he argues, learners will no longer be dependent on others who own such knowledge. This pure knowledge, he suggests, brings learners beyond their common-sense understandings of their daily experiences and enables them to conceive of alternative and new possibilities beyond these daily experiences. However, having access to this disciplinary knowledge and being able to use it in these ways is very complex, especially when the disciplinary knowledge is imposed on learners at such a young age, and when they have had little time to develop informed 'common-sense' concepts. John Beck (2013) suggests that even at higher levels of schooling:

Enabling students to make subjectively meaningful connections between these necessarily remote disciplinary worlds and the student's everyday experience may prove to be one the most challenging and enduring educational problems that face us (187; original emphasis).

Our study interrogated some Egyptian primary pupils' comments about these connections between the disciplinary and the common-sense knowledge of English. Through our study, we aimed to consider in detail how these connections between classroom learning and community learning may be facilitated, and what the implications are for underprivileged

6 
pupils' wellbeing. We look for messages relevant both to the primary schools of Egypt and to those of other countries sharing similarly closely classified and tightly framed curriucla, in relation to the common aim of improving the social justice of all societies.

\section{Research design}

The research question for this study was: How do primary pupils experience the traditional classroom and what suggestions do they and their teachers express for making improvements to English language learning? The aim was to elicit and understand in depth how disadvantaged primary school pupils perceived their experiences of learning Englishin schools, in a school system whereby boundaries between school and community knowledge were strong, and the pupils' control of the classroom was weak. The research questions were deliberately open-ended in order that as researchers we did not impose assumptions on pupils. Our starting point was the recognition that little interaction occurred between pupil and teacher or pupil and pupil in these language classrooms and we wanted to investigate the sense pupils made of learning language without planned occasions for practising it orally. We knew that in better-resourced schools, such as privately owned 'international' schools in Egypt, this traditional approach had been somewhat dismantled. Our methodology was interpretivist whereby we valued and explored the interpretations and meanings expressed in individual pupils' narratives. We agreed with Saunders et al. $(2007,106)$ that this paradigm adopted an 'epistemology that advocates the need for the researcher to understand the differences between humans in their role as social actors'. As a team of researchers, two Egyptian and one English, we used four data collection methods in two stages of research:

First stage: November 2015

\section{7}


1. Observation of 18 lessons, including English lessons, in three schools attended by disadvantaged pupils in Alexandria, Egypt;

2. Written responses of 393 pupils in these lessons to sentence-starters.;

Second stage: April 2016

3. Individual interviews with 38 pupils; and

4. Group Interviews with English teachers in each school.

The research context was the English language teaching of poorly-resourced primary

Formatted: Font: Calibri schools in Egypt. Access to state schools in Egypt is exceptionally difficult to obtain but we managed to gain We gained access in Alexandria, Egypt, to three government-funded, under-privileged-primary schools of three-different types: one Islamic school; one 'official language' school; and one 'mainstream' school. In the first two schools, as is common even in the least privileged communities in Egypt, some minimal fees were paid by parents; and in the third, no fees were paid at all. These latter are the least privileged schools in the country. Altogether we had the following participants:

Islamic school = 88 pupils [27 BOYS; $61 \mathrm{GIRLS}]$.

Official language school = 196 pupils [92 BOYS; 104 GIRLS].

Mainstream school = 110 pupils [61 BOYS; 49 GIRLS].

TOTAL = 394 PUPILS

Girls $=214$

Boys $=180$ 
However, one girl declined to complete the sentences so the total number of sentencestarter tasks completed was 393.

\section{Observation}

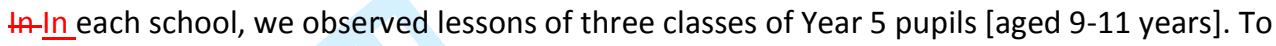
familiariszze the pupils with ourselves, we firstly observed each research class during a lesson in a subject other than English. The three of us next observed and made field-notes about an English lesson for all theeach classes. Each of us researchers focused on a particular group of pupils in class and we were non-participant during the lesson. After each observation, the three of us compared our observations and collated our notes. Our main focus was the relationship between the actions of the teacher and the responses of the pupils. In particular, we noted: pupils' opportunities for collaboration, talking in English, $\underline{\text { using self-assessment, receiving formative teacher feedback, engaging in differentiated }}$ tasks, engaging in dialogue with the teacher, having choice and linking learning to home.

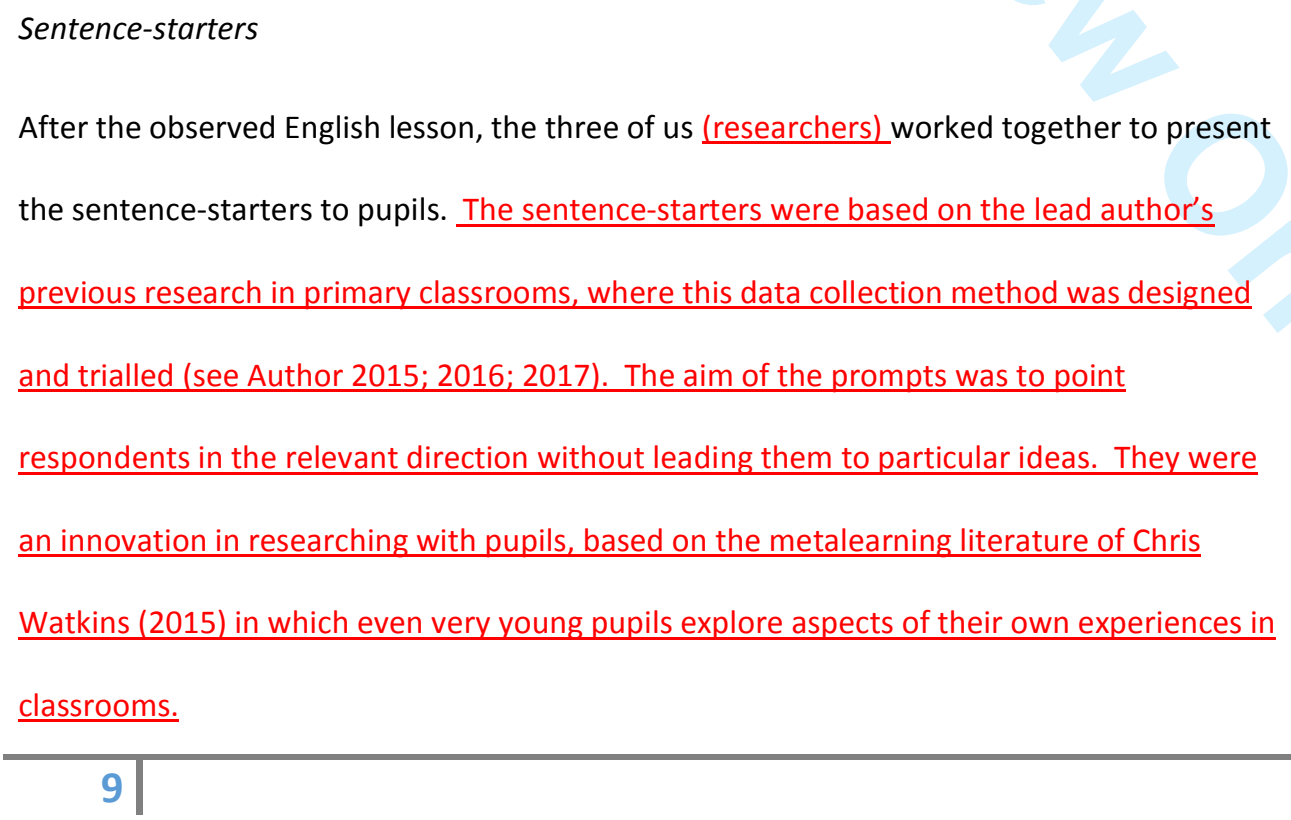




\section{Educational Studies}

We took time to explain to pupils in detail what the purpose of the research was and what we would do with findings. We also answered their questions about the research. We explained that pupils' individual names would never be revealed in publications of findings (pseudonyms are therefore used for pupils and teachers, below, without reference to their schools). We gained the pupils' face-to-face consent before carrying out any activities with them. We also gained the teachers' and principal teachers' written consent. This research, both in its design and fieldwork, therefore adhered to the BSA ethical guidelines (2002).

In every classroom, as children completed the sentences, the two Egyptian researchers in our team went around the class giving support where necessary, but without putting any answers into pupils' minds. The responses were transcribed and translated by our two Arabic-speaking team members. The sentence-starters included the following:

1. In the English class where I benefit most, I feel...

2. The things I do in the English class where I benefit most are...

3. The things I do in the English class which do not benefit me are...

4. The teacher who helps me learn best is...

5. I want to learn English so that I ...

Individual interviews

$\underline{\text { Individual interviews were our key source for investigating pupils' complex insights. }}$ Although we invited nearly 400 pupils to write responses to sentence-starters, by interacting individually with 38 carefully selected interviewees, we were able to ask and respond to diverse questions and thereby explore identified issues in depth. We selected the 38 interviewees by reading through the sentence-completions and selecting those who 


\section{Group Interviews}

Islamic school: 1 hour 53 minutes; 9 teachers

\section{1}


Official language school: 1 hour 30 minutes; 6 teachers

Mainstream school: 1 hour; 4 teachers.

The aim of the Group Interview was to hear the perspectives of the teachers about pupils' responses to the sentence-starters. In each Group Interview, we presented one pupil sentence-completion at a time and we invited the teachers to predict how the pupils would have responded during the sentence-completion exercise. We then fed back to them the actual responses from the pupils across the three schools. Finally, we invited the teachers to reflect on and comment on all the pupil responses and make suggestions.

Analysis

As a team, we analysed responses using inductive approaches whereby we tried not to impose our own categories on the pupils' (or teachers') responses but rather attempted to let themes emerge. We based our approach on the grounded theory described by Charmaz (2014). In our presentation of themes that emerged, we have aimed both to indicate dominant trends and to illustrate insightful special cases. 
We were somewhat surprised initially to find that pupils seemed to be engaged and concentrating well on the lesson. In Bernstein's own words, they seemed to possess 'a passive willingness to accept "doses of training and retraining as prescribed by government"' (Beck 2013, 181 citing Bernstein, 2000). This behaviour was explained somewhat when we interviewed pupils. We found that these children had very high ambitions for their futures and believed that learning pure, school English was instrumental in helping them to achieve these ambitions. Underlying pupils' aspirations, there seemed to be a concept of an 'educated' citizen (Peters 1965) who knew the pure English and because of this, had prestige in society, as suggested by Bernstein (1971). They aspired to become this educated citizen in order to have status in society. In the 393 sentence-completion responses, there were 87 


\section{Educational Studies}

pupils who specifically mentioned becoming educated by learning English and 74 pupils who described wanting to learn English to improve the 'level' of their lives. There were 89 pupils who mentioned getting a good job or working in a university through their command of English; while no fewer than 58 pupils detailed wanting to learn English to become a doctor specifically.

It is noticeable that they aspired to become a more 'educated' person than their parents had been, with a more socially prestigious job and a higher 'level' of life. For example, ten out of the 38 interviewees aspired to become doctors and six to become engineers and for both, high level English was required for study at university. In contrast, there were no interviewees' parents described as doctors and only two as engineers. Parents' semi-routine or routine work included factory worker, taxi driver and hotel worker. Ten interviewees told us that their mothers were housewives but not a single girl suggested that she would become a housewife. What we noticed, in other words, was that these pupils were seeking to become educated and improve their future careers over those of their parents, to work in more elite professional jobs than their parents. Learning English as a school subject featured in their responses as one crucial way to make this social move. In other words, we perceived that the pupils saw English both as intrinsically worthwhile in Peters' (1965) sense as constituting the educated person; but also as a powerful tool for social mobilisation in Young's (2013) sense. What is also clear is that these pupils sought to fit in with the social definition of an educated person in their culture and then to use their subject knowledge to improve their own position within that society - rather than changing the society itself in a critical way.

Pupils were adamant about the importance to them of acquiring the disciplined knowledge 14 
provided by the teacher, even if the pupils told us that they often found grammar rules and structures very hard to grasp. For most students, therefore, the main emphasis was on having a teacher who could 'explain the lesson' clearly, which was the key ingredient in their acquisition of the designated knowledge. This referred especially to grammar rules and structures. Hana reflected this common view. She told us about the ideal teacher:

She explains quietly, step-by-step. She does not shout. She explains in a quiet and gradual manner. She does not get irritable easily. She repeats her explanation when someone has a problem understanding. When a student tells her that s/he does not understand something, she does not insult them or call them names... She explains again instead.

Hana reflected many other pupils' views in her emphasis on the teacher's kindness but without challenging the teacher's role as that of knowledge transmitter of a particular and essential body of knowledge that was not easy to access directly. Furthermore, most pupils believed that some harsher discipline processes were justified to some extent as the only way to transmit difficult curriculum content effectively. Mahmoud told us that for 'weak' students who failed to understand well, 'We give them a chance and if they keep making mistakes we hit them'. In other words, this punitive culture was accepted by many pupils as the best, perhaps only, way to get pupils to reach the challenging, prerequisite level of the English curriculum in the right amount of time.

Many pupils' persisting focus on learning via the written word rather than on conversational English, was highlighted when we asked children about how they would teach a foreign child Arabic. They seemed to find it hard to conceive of language learning through speaking and listening. They recommended teaching the foreign child to learn the

15 


\section{Educational Studies}

alphabet in Arabic first and to read vocabulary before allowing the foreign child actually to use the language. For example, Rana believed the following when we asked her advice for a foreign child learning Arabic:

If he [a foreign boy] learns the alphabet, he can form any word... When he learns the alphabet, he can learn words and sentences. I will make him practise saying the words he needs. If he knows the words, he can form the sentences on his own. Surprisingly, even the internet was seen by some pupils as a source of information to help pupils memorise rules and vocabulary rather than a site for learning to speaking as well as read and write. For example, Mahmoud explained how, if teachers had access to IPads or tablets, they should: 'Ask the pupils to use their tablets to search dictionaries and then ask them to recite what they learnt'. In other words, he was not asking for new content of English lessons, only a new instrument to deliver traditional content to help them to better meet the traditional goals of becoming educated.

\section{Pupils engaged in outside-school English language learning to supplement the school curriculum}

Given these findings, we were surprised to discover that, when asked through the sentence-completions about their key motivation for learning English at school, the largest proportion of both boys and girls chose speaking English ( $n=166)$; and learning English to travel abroad $(n=138)$. The chances of these disadvantaged pupils actually travelling abroad at any time in their lives were in reality minimal. However, these aspirations illustrate that they were not only interested in being educated in the school's pure English, despite its current and future potential advantages, but they also wanted to be able to apply it by speaking it. At present, applying or speaking English rarely occurred in the 
school classrooms and the use of peers as practice-partners was almost non-existent. No examples of spontaneous or open-ended English speaking were observed in the classes we attended. Only occasional structured interaction with the teacher was detected. Despite this, it seemed that the pupils had perceived a need to use their English as well as to learn the pure form. It appeared then, that pupils still aimed to improve their social status, but did not see the learning of classroom English as the only means for achieving this. There appeared to be some tension between the two Englishes they aspired to learn. On the one hand was the pure English that was a sign of being educated and that allowed them to pursue prestigious subjects at university and thus progress socially via the traditional route. On the other hand, however, these disadvantaged students did seem to be questioning the completeness of the pure English in terms of serving their current and future needs.

Our analysis led us to believe that pupils' desire to speak English related to the pupils' 'imagined community' of English speakers whom they perceived as a community of educated, high status, international people who inhabited 'advanced' countries and who spoke English (Anderson 1991; Kanno and Norton 2003; Norton, 2001; Norton and Kamal 2003). Therefore, contrary to expectation, these children were not only trying to pass their school exams to achieve elite status as doctors and engineers but they perceived - albeit faintly as yet - another route to join an elite as well. This alternative route was that of joining the international English-speaking community, whose English was different from classroom English, yet a related and potentially legitimate means for social mobility. Reem explained: 


\section{Educational Studies}

When I travel abroad, I need English to finish deals with business people. They don't speak Arabic and I want to speak English not Arabic so that I could do whatever business I want.

Merna reflected her desire to identify fully with the imagined community, not only as a business person:

I would like to ... travel abroad and to be able to talk to people there and be like one of them. I wish to live abroad... I wish I could be like them and speak English like them.

These pupils emphasized the importance of learning beyond the teacher in the classroom. They referred to some online methods, similar to the online methods used outside school by English pupils (Furlong and Davies 2012). However, in Egypt, online learning was only one possible means (sometimes also not possible) among a range of pupils' suggestions for speaking and listening to English outside school. In these examples, they were showing some challenge to the control of the teacher over their limited subject domain. For example, Ossama advised $\theta$ fother pupils:

They should search the internet and read subjects and not rely only on the school ... you shouldn't depend on the teacher. You should have access to other resources...

Reem, among others, had noticed that pupils who took initiatives in improving their English in diverse ways beyond the reach of the teacher, seemed to be more immersed in the English language generally:

Those who are very good at English watch lots of films and depend on themselves... the more we listen [to other English speakers], the more we learn. 
One teacher noted this tension between the (disciplinary) content taught by teachers and the (spoken) English taught by others. This teacher mentioned 'real life':

In real life, when they [pupils] listen to English songs, someone speaking English, they feel that they haven't learnt English at all [at school].

The teachers thereby also seemed to be questioning the completeness of the pure English of the classroom teacher and recognising the value of applied English, especially for these students who were from underprivileged backgrounds.

Some pupils in our study had discovered more participatory means for learning English including interactive activities in which another English speaker might provide them with feedback by modelling English. They noticed that this English could contain any number of words and sentence structures that they had not officially 'covered' in lessons. During this process of adding to the school English lessons, a few pupils had begun to encounter other models of English itself: this was perhaps how they realised that classroom English was not the only English that they needed to learn in their pursuit of social success. They had discovered that they could, and perhaps should, use siblings, parents, tourists and YouTube to engage in learning conversations, in addition to learning the school English. For example, although Merna was clear that in class the pupil's role was to be silent and to pay attention to the teacher, at home she would follow up any questions she had by making up her own sentences to use with her parents. Merna explained:

I study the English words by heart but if there is a word I cannot read my father will read it for me... when I learn a new word in English, I try to put it in a sentence and say it to my mother. 


\section{Educational Studies}

Perhaps the most striking example of a pupil engaging in diverse means for learning the spoken language was Yulia's vivid picture of learning English by playing games using the English language with her older sister:

We just play a game [using English] of characters, animals and birds... We also talk about films [in English]. I usually check if she understands me or not and she does the same with me... We get videos from YouTube and talk about them.

However, it is important to note that such support was only available to those pupils whose parents or siblings spoke some English or who could afford to pay an expert private tutor. Ossama explained how, when accessing additional resources, he would use digital sites to listen to spoken English. However, this access also depended on the availability of particular (expensive) English language TV channels:

When I watch Disney Channel and listen to them speaking English all the time, I listen to them and learn new expressions. I mean, it helps me to learn good English.

When we asked Meera in interview how Egyptian pupils could learn to speak like the characters she encountered in English-medium films, she paused, then replied: 'But we can't be like them'. After further pause, she changed her mind and decided that such learning could occur - but not in school classrooms:

Meera: But we could speak like them if we had courses.

MM: Where could you have courses? In schools?

Meera: No!

MM: So where would these courses be taught?

Meera: In institutes ... any place.

20 
For her, the school's role was to teach one English while outside school, students could learn a different kind of English, applied English, in a range of different ways. Pupils with enough resources could attend 'institutes' and/or take private lessons to learn the remaining aspects of English.

Our analysis of this situation relates to the need for pupils' prolonged informal initiation (Beck 2013,189) in order to access entry into the aspired community. It seems that these pupils were aware of an alternative English that was part of the 'cultural capital' necessary to make social progress. Some of them had some inkling, as yet indistinct, that disciplinary English, transmitted by the teacher, was essential but not sufficient. Some pupils mentioned that Egyptian children who attended English-medium (international) schools thereby had easy access to that additional set of qualities that were needed to become part of the elite. At age 10, the sample pupils still had high, albeit perhaps unrealistic, hopes to overcome the obstacles of disadvantage, using an array of rather random out of school methods. But at age 16 , as they enter the stiff competition for university places, it is intriguing to know how they will perceive their chances then. Another research project needs to address this topic.

\section{Peer learning and its potential for connecting the pure English to the applied English}

It was noticeable from our observations that almost no sanctioned peer learning seemed to be occurring inside the English classroom. It actually became clear during individual interviews that pupils found it hard to imagine that other pupils could be part of their learning in the classroom. Several pupils said they preferred to work alone and have the teacher correct their mistakes. For example, Moussa said: 'We prefer teachers' corrections more as we are used to it and the teacher knows better... it is the teacher's work'. In other 


\section{Educational Studies}

words, he hinted that the purpose of learning was to acquire the true English owned by the teacher and to have impurities stamped out immediately by the teacher.

On the other hand, there were some interviewees who saw a role for peer correction to support the learning of classroom English. For example, one pupil, Donia, saw that: 'When I make a mistake and [peers] correct me, I know that I have made a mistake and I will learn from mistakes'. Going beyond mistake-correction, however, a small handful of children proposed some further diffusion of teaching, in the form of pairwork among pupils in the classroom which entailed pupils actually constructing spoken sentences in which they applied the pure knowledge to the spoken word. Mostafa, for example, proposed that if he were the teacher:

I would pair them [pupils] to ask and answer each other... There are passages they would read and they would form sentences using the words in the passage.

In the individualist culture that had been nurtured to protect the purity of the subject, this lack of experience with collaboration was not surprising. However, its lack appears to mitigate against these pupils' acquisition of the very knowledge that their poverty obstructed, the means for connecting their curriculum knowledge to everyday life beyond the school. Families with more resources did not need their children to practise speaking English in the classroom as they had opportunities for practising English outside school. In addition, they were more likely to have access to the internet than less advantaged pupils. These privileged children needed the disciplined knowledge of the classroom as the aspect of curriculum that they could not access informally. For the disadvantaged pupils, however, the classroom might be the best opportunity they had for connecting the institutional and the vernacular and becoming more initiated into the culture of English in its wider social sense.

22 


\section{The potential of pupils learning the spoken word through the internet}

One means whereby the pupils in our sample could improve their immersion into the wider culture of the English language was through the internet. However, because of their lack of resources, the internet was neither widely accessed nor widely used for learning by the pupils in our sample. However, among a few interviewees, there were some quite innovative ideas about teachers harnessing digital technology to teach an expanded version of English in the classroom which sometimes included a focus on the spoken language. This of course would depend on internet being available in schools and in pupils' homes, which was not always the case. Reem had some insightful ideas, in cases where internet was available:

Teachers would explain the lesson then ask us to search for a similar topic on YouTube. We would watch it but not memorize it, and then we could write about it on our own.

Merna noted the collaborative potential of preparing (written) work at home to then share in class:

[We could] use the internet to write our own topics and prepare PowerPoint presentations with pictures and writing. I would access useful sites and chat with my friends and we could use the camera to see each other.

Lobna, among others, proposed teachers using a laptop with pupils to show 'how pupils in England talk' and also 'how pupils [in England] learn'. It seemed that she almost perceived the traditional teacher as a barrier to her full English learning:

I want technology... I need a small Ipad instead of textbooks because now pupils like Ipads not textbooks... If they had Ipads, they would interact with each other.

\section{3}




\section{Educational Studies}

Carmen suggested a different solution to the disconnection between disciplinary and common-sense knowledge:

We can have the school book on the internet. It will be easy to study and I will like English. It will be better than taking private lessons. I will speak in English... I and my friends can learn together and share things over the internet.

These pupils wanted to add to the insulated content and tightly framed pedagogy of the classroom, to embody a less strongly-framed pedagogy whereby outside stimuli could be incorporated, especially drawing on the spoken (applied) word as used among communities of English speakers. In these select examples, the pupils indicated that they were already engaging in, or prepared to engage in, additional - applied - English knowledge but that they wished for this to be introduced into the classroom so that all pupils could benefit from it, not only the more privileged.

\section{Discussion: mitigating against disadvantage by challenging the pure curriculum}

\section{Our research question was: How do primary pupils experience the traditional classroom and} what suggestions do they and their teachers express for making improvements to English language learning? By analysing the words of the 394 underprivileged pupils in our study, in particular those of 38 interviewees, we perceived that they described experiencing English learning in two distinct senses: acquisition of English in the traditional classroom as the pure school discipline, which they believed was the passport for them to become more prestigious within traditional structures of society; and immersing themselves in verbal interaction with others, which they believed would enable them to become part of a wider community and enhance their identities in an alternative (albeit related) way. This dichotomy was of interest in terms of considering the nature of knowledge that is valuable

\section{4}


to disadvantaged pupils. Although pupils in this research conformed to traditional approaches in many ways, there were signs that they needed something more, if they were to achieve their desire of becoming part of an international English speaking community who had high status globally and in their country too.

\section{In relation to the second part of our reseach question, suggestions of pupils for making}

improvements to English language learning, wWhat became evident from our pupils'

narratives ${ }_{2}$, was that some children seemed to believe that to qualify as valuable English knowledge, the English subject in the classroom should include spoken (applied) aspects, useful in everyday life. In other words, they were questioning the adequacy of the pure English in the traditional classroom, disconnected from the applied English, in terms of its potential usefulness. Within their expanded models of learning English, pupils described situations where learning tasks and activities were more interactive than currently in the classroom. Relations in such a learning environment would become more diffuse and less concentrated between learner(s) and teacher(s). If this expanded framework of applying English language knowledge were incorporated within the classroom, pupils who had little or no access to conversational English outside school could at least obtain some exposure to it in the classroom. In addition, they might also find the experience of learning English more active and perhaps enjoyable.

It may be that these disadvantaged pupils themselves had come to experience and perceive how the traditional form of 'specialization' on its own kept them apart from, rather than in 'communality with' a wider (this time more privileged) community (Bernstein 1971, 55; original emphasis). In terms of social justice, the implications of this finding were that opportunities for speaking in the classroom needed to be increased, whether through more 25 


\section{Educational Studies}

use of digital technology in class (if internet wereas available) or through use of peers in the classroom for practising speaking. It seems that for these less advantaged children, digital technology was not often available outside school. The school would therefore do them a service by making it more available inside school if possible. This would mean that, while these children could not benefit outside school from the English language on the internet as did their more advantaged peers, at least they could brush with these opportunities within class.

More simply, however, pupils perceived and expressed that their lack of experience with the niceties of the spoken language outside school, at home and socially, could be compensated for by more interactive learning tasks within the classroom. If their families and friends did not have familiarity with spoken English, at least the children themselves could gain some practice by speaking with peers in the classroom. One simple way of managing even in large classrooms, as suggested by the sample interview pupils, is using pair work whereby every pair of children in the classroom practises certain sentences with each other, all at the same time. This way, every single child has a chance to practise the spoken word, every lesson. This is a message that traditional classrooms in other countries, for example, in the Middle East,Africa, China, India and Pakistan, and beyond, might find useful too, if they currently sustain insulation among subjects and strong boundaries between pure and applied knowledge.

Change of the nature of classroom behaviours is likely to be resisted by the traditionally more privileged strata of societies because of its challenges to elitist structures of power, authority and identity. This is because the elite have their own (private) access to ways of completing their process of becoming 'educated' through initiation at home and in social life.

26 
However, a progressive shift which benefits the less advantaged in society will be helped by a new pedagogy based on the explicit linking of the traditional curriculum to the language of communication used globally and locally. In Egypt, a pedagogy including frequent opportunities for pair work among all members of the class simultaneously will be well suited to the large numbers in Egyptian classrooms. At the same time, it will help to provide opportunities for less advantaged pupils to link principled knowledge to applied English in a more 'subjectively meaningful way', as expressed by pupils in our sample. In Young's words, cited earlier: 'Parents send their children to school expecting them to acquire the specialist knowledge that they would not have access to at home' $(2013,107-108)$. In the case of less advantaged children in Egypt, as in өthersimilar countries, ironically this specialist knowledge may transpire to include vernacular English.

\section{REFERENCES}

Anderson, B. 1991. Imagined Communities: Reflection on the Origins of Nationalism. Verso: London.

Asassfeh, S., Khwaileh, F., Al-Shaboul, Y., \& S. Alshboul. 2012. Communicative Language Teaching in an EFL Context: Learners' Attitudes and Perceived Implementation. Journal of Language Teaching and Research, 3(3), 525-535.

\section{Author 2015}

\section{Author 2016}

Author 2017

Barton, D., and Mary Hamilton. 2012. Local Literacies: Reading and Writing in One

Community. London: Routledge.

27 
Beck, J. 2013. Powerful Knowledge, Esoteric Knowledge, Curriculum Knowledge. Cambridge Journal of Education 43(2): 177-193.

Bernstein, B. 1971. On the Classification and Framing of Educational Knowledge, in: M. Young (Ed) Knowledge and Control (pp.47-69). London: Collier MacMillan.

Bernstein, B. 2000. Pedagogy, Symbolic Control and Identity: Theory, Research, Critique. Lanham, MD: Rowman \& Littlefield.

BSA, British Sociological Association. 2002. Statement of Ethical Practice. http://www.britsoc.co.uk/media/27107/StatementofEthicalPractice.pdf Field Code Changed

\section{Charmaz, Kathy. 2014. Constructing Grounded Theory. London: Sage.}

Dann, R. 2002. Assessment as Learning. London: RoutledgeFalmer.

Fairclough, N. 2014. Critical Language Awareness. London: Routledge.

Freire, P. 1970. Pedagogy of the Oppressed. London: Penguin.

Furlong, J. and Chris Davies. 2012. Young People, New Technologies and Learning at Home:

Taking Context Seriously." Oxford Review of Education 38, no. 1 (2012): 45-62.

Hoadley, U. 2006. Analysing Pedagogy: The Problem of Framing. Journal of Education 40: 15-

34.

Hoadley, U. \& J. Galant. 2016. Specialization and School Organization: Investigating

Pedagogic Culture. British Journal of Sociology of Education 37(8): 1187-1210, DOI:

$10.1080 / 01425692.2015 .1042149$

Holliday, A. 1994. Appropriate Methodology and Social Context. Cambridge: Cambridge University Press. 
Kanno, Y., \& B. Norton. 2003. Imagined Communities and Educational Possibilities: Introduction. Journal of Language, Identity, and Education 2(4): 241-249.

Lin, A.M. 2007. What's the Use of 'Triadic Dialogue?': Activity Theory, Conversation Analysis, and Analysis of Pedagogical Practices. Pedagogies: An International Journal, 2, 2, 77-94.

Liao, X. 2004. The Need for Communicative Language Teaching in China. ELT journal, 58(3), 270-273.

Nassaji, H., \& G. Wells. 2000. What's the Use of 'Triadic Dialogue'?: An Investigation of Teacher Student Interaction. Applied Linguistics 21: 376-406.

Norton, B. 2001. Non-participation, Imagined Communities and the Language Classroom. Learner Contributions to Language Learning: New Directions in Research 6(2): 159-171.

Norton, B. \& F. Kamal. 2003. The Imagined Communities of English Language Learners in a Pakistani School. Journal of Language, Identity \& Education 2 (4): 301-317.

Nunan, D. 2003. The Impact of English as a Global Language on Educational Policies and Practices in the Asia-Pacific Region. TESOL quarterly, 37(4), 589-613.

Peters, R.S. 1965. Education as Initiation, in R.D. Archambault (Ed.): Philosophical Analysis and Education (pp. 87-111). London: Routledge \& Kegan Paul.

Richards, J. C., \& T. S. Rodgers. 2014. Approaches and Methods in Language Teaching. Cambridge University Press.

Saunders, M., P. Lewis, \& A. Thornhill. 2007. Research Methods for Business Students. Prentice Hall: London.

Watkins, C. (2015). Meta-learning in Classrooms. In [Author].

29 
30

White, J. 2012. Powerful knowledge: Too Weak a Prop for the Traditional Curriculum. New Visions for Education Group, available at http://www. newvisionsforeducation. org. uk/2012/05/14/powerful-knowledge-too-weak-a-prop-for-the-traditionalcurriculum.

Young, M. 2013. Overcoming the Crisis in Curriculum Theory: A Knowledge-based Approach. Journal of Curriculum Studies 45(2): 101-118. 